\title{
Shaft hoist rope wear condition as a diagnostic signal
}

\author{
Eugeniusz Mańka ${ }^{1}$, Michat Styp-Rekowski², Maciej M atuszewski ${ }^{2, *}$ and Danil Y. Pimenov ${ }^{3}$ \\ ${ }^{1}$ R esearch and Supervisory Centre of Underground M ining Co. L td., L edziny, Poland \\ ${ }^{2}$ University of Science and Technology in Bydgoszcz, Faculty of Mechanical Engineering, \\ Bydgoszcz, Poland \\ ${ }^{3}$ South U ral State University, Department of Automated Mechanical Engineering, Chelyabinsk, \\ Russia
}

\begin{abstract}
In the paper there were discussed factors which determine wear process intensity of shaft hoist rope. The ropes as the element or the elements set are appearing in numerous, diverse machines and mechanisms, fulfilling the most different functions in them. M ining shaft hoists are a very representative example of the object being used for a vertical transport, of both the staff of the mine and winning. Results of experimental investigations of rope were presented. Findings obtained different methods were compared.
\end{abstract}

\section{Introduction}

The reason for functionality loss of the elements forming friction nodes is limited wear resistance their surface layer on the damaging effects of external forces. Influence of these factors (mechanical, thermal, chemical, electrical) over the cooperation of kinematic pair, causes changes in the surface layer. These changes are generally the reason of loss kinematic pair ability to fulfill the design-related functions in a different grade. The knowledge of the changes taking place makes it possible to forecast the condition of a technical facility [1-7].

The ropes as the element or the elements set are appearing in numerous, diverse machines and mechanisms, fulfilling the most different functions in them. They are elements used, for example, as flexible connector in control systems, they are used also for an transfer operation of axial load in changeable directions in transport systems, both horizontal and vertical. As the constructional element moving axial forces with significant values steel ropes are applied, e.g.: in the construction (goods and personal lifts, reinforcing concrete), in the mining for the vertical and horizontal transport and in other branches of industry, as a different kind of tension members, being used for a transport of materials and people. Relatively great durability and a reliability are a major advantage of ropes. This second feature results from it, that the rope has a parallel constructional structure what causes, that in case of damage one or a few structural components (wire) loss of the ability of the whole system, in which its is existing isn (-taking place [8-12].

This article describes basic factors which determine intensity of the rope wear process. The basic type of identified operating loads are force induced loads. Since the working environment of shaft hoists is chemically active, the second significant type of loads are environmental loads. The performed analysis was based on the lifting rope of a shaft hoist, and the scope of the tests was limited to force induced loads, as these are factors which determine the tribological wear process. To ensure safety of shaft hoist lifting ropes, it is necessary to know their actual technical condition. A possible failure may lead not only to

* Corresponding author: matus@utp.edu.pl 
serious property damage but also injury or death. Because of such extensive, partially irreversible effects of failures, rope tests are very detailed and therefore time-consuming.

The objective of comparing the results of different strength parameters of structural elements of the rope (wires) was to verify whether it is possible to limit the scope and number of rope tests without compromising safety of the hoist.

\section{Tested object}

The object tested in this research was a 3-strand rope with a $34 \mathrm{~mm}$ diameter, which meets the requirements of the standard [13].

This is a double strand rope consisting of wires twisted into strands, which are then twisted into a rope on an organic core (sisal core). This case deals with a left lang-lay rope (wires twisted into strands and strands twisted into ropes twisted in the same direction). The strand in the rope is twisted of three layers of a wire. The structure of the rope provides a point contact between the particular layers of the wire.

Each strand consists of the following structural elements presented in Figure 1:

- internal layer made up of 6 wires with a $1.38 \mathrm{~mm}$ diameter, onto which three filler wires are wound, with a $0.70 \mathrm{~mm}$ diameter each,

- middle layer consisting of 12 wires with a $1.54 \mathrm{~mm}$ diameter,

- external layer consisting of 13 wires with a $2.32 \mathrm{~mm}$ diameter.

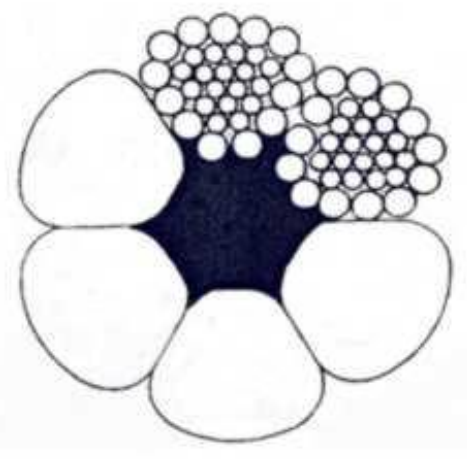

Fig. 1. Constructional structure of tested rope.

B elow are some of the characteristic features of the tested rope:

- nominal load bearing section of the rope (total of wire sections with the nominal diameter): $517.5 \mathrm{~mm}^{2}$;

- $\quad$ total breaking force of wires (M BF) as per the manufacturer's certificate: 846,020 $\mathrm{N}$;

- force fully breaking the rope: $755,800 \mathrm{~N}$.

A $100 \mathrm{~m}$ rope section $\left(L_{0}-100 \mathrm{~m}\right)$ was taken for the tests. The sampling place is shown in Figure 2 - it was situated (beginning of the sample) approximately $80 \mathrm{~m}$ above vessel $A$. $M$ agnetic tests [14] showed that the largest weakening occured in this place - the largest loss in the section. According to the kinematic analysis of the machine operation, this segment was mainly tensed during the operating period; however, it was also bent on drive drums and pressing drums. 


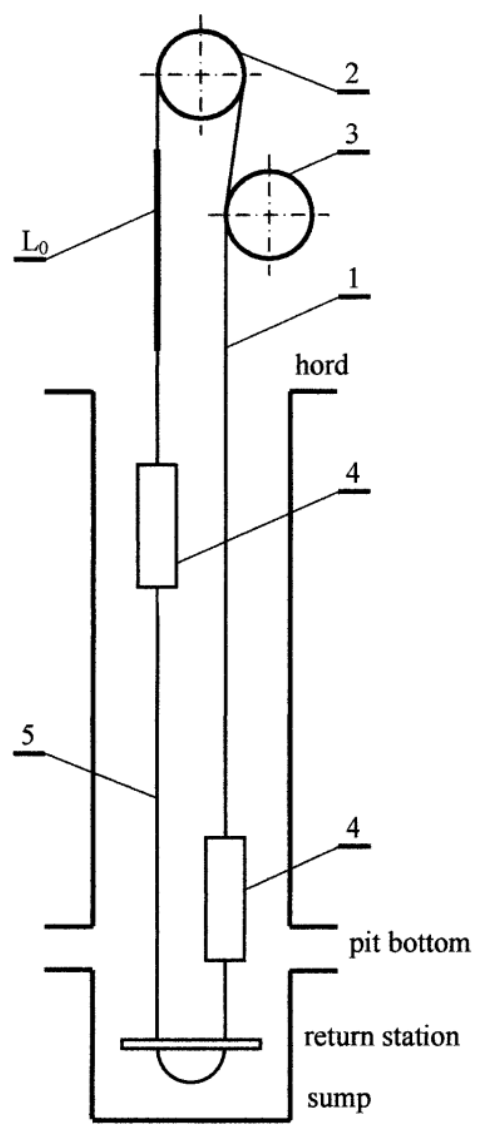

Fig. 2. Scheme of shaft hoist: a) shaft hoist - operational scheme: 1 - lifting rope, 2 - Koepe pulley, 3 - pressure wheel, 4 - hoisting vessels, 5 - balance rope, $L_{0}$ - rope section collected for the tests.

The rope was used in an 820 m deep dowcast shaft, in a 4-rope machine with a medium traffic volume - approximately 150 hoists/24 hours. It was removed after 36 months of operation.

\section{Rope wear process}

The performed analysis, supported with knowledge about structure and operation of shaft hoists, indicated that the following elementary processes are the basic reason for rope wear.

- abrasion wear,

- corrosion wear (oxidation, corrosion: chemical or electromechanical),

- fatigue wear (surface or volume).

Depending on conditions under which hoists are operated, as well as on their structural properties, inclusion of particular components may vary. All the elementary processes above have one common feature - they are classified, in full or partially, as tribological wear processes [15].

As a result of all the above processes, material traits degrade due to changes in the structure of the construction material and change in geometrical traits caused by friction. It should be emphasized that strong synergetic effects of elementary processes occur here, e.g. oxidation and friction. The above elementary wear processes occur simultaneously, 
therefore determination of participation of a particular process in overall weakening of the rope is practically impossible. Tests indicate a summarized effect of all of the occurring processes.

\section{Test metodology}

As described in the previous section, tensing is the basic load affecting a hoist bearing rope. Because of the hoist structure, tensing of the line is accompanied by cyclical bending (on drive wheels, pressing wheels and directional wheels). Moreover, particular wires are additionally twisted due to the rope structure. Thus, such complex state of load means that standard strength tests of rope parts (wires) concern the following elements and include three stages:

- tensile test [16],

- bend test [17],

- torsion test [18].

Their results can be compared with results of the force breaking the rope in full [19], however, the weakening level of the rope is significant in this case - not its absolute value.

The breaking test of single wires was performed on a strength test machine type FM 1000, manufactured by WEB Rauestien in accordance with the currently applicable standard. The technical parameters of the machine are as follows:

- measuring ranges: $0 \div 2,000 \mathrm{~N}, 0 \div 5,000 \mathrm{~N}, 0 \div 10,000 \mathrm{~N}$,

- tensing speed: $10 \div 30 \mathrm{~mm} / \mathrm{min}, 30 \div 90 \mathrm{~m} / \mathrm{min}$,

- reading accuracy: \pm 1 .

The torsion test was performed on a PU -S/M L/15 type RM -510 torsion test machine equipped with a set of weights used to obtain a required tension of the wire.

During torsion tests of single wires of particular rope strands, wire endings are put into two holders (rotating and immovable) situated at a distance of equal to 100 wire diameters. This value refers to diameters of wires in the tested rope, since the distance between the holders is varied for different ranges of diameters. During the test, a wire is loaded with an axial force not exceeding $2 \%$ of the value of the nominal breaking load of the wire. The test is performed until the wire is broken or the number of torsion cycles required by the respective standard is acquired. For diameters of wires of the tested rope, the maximum number of torsions per second is 1 .

Torsion tests of individual rope strand wires are carried out separately for each layer of the strand. The minimum number of torsion and bend cycles for a single new rope wire in terms of particular layers is given in Table 4.

The bend test was performed on a PU-S/M L/52 bend test machine equipped with a set of bending rollers with the following diameters: $5 \mathrm{~mm}, 7.5 \mathrm{~mm}, 10 \mathrm{~mm}, 15 \mathrm{~mm}, 20 \mathrm{~mm}$, and guiderails with holes matching respective diameters of the tested wires.

During a bidirectional bend test of rope wires, a sample fixed by one end to the holder is bent by $90^{\circ}$, in directions opposite to the rollers with particular diameters. Bend shaft diameters depend on diameters of tested wires. Diameters of tested rope wires are as follows: $3.75 \pm 0.1 \mathrm{~mm}$ - wire with a $1.38 \mathrm{~mm}$ diameter; $5.0 \pm 0.1 \mathrm{~mm}$ - wire with a $1.54 \mathrm{~mm}$ diameter and $7.5 \pm 0.1 \mathrm{~mm}$ - wire with a $2.32 \mathrm{~mm}$ diameter. One bending cycle consists of a $90^{\circ}$ vertical deflection in one direction followed by a vertical retrace.

The bend test is performed separately for each strand layer because of the necessity to use bending rolls with specific diameters. The bending frequency should not exceed $1 \mathrm{~Hz}$.

The above strength tests are carried out on single wires. A sample segment of a rope is untwisted into strands as per the structure (this concerns multi-layer ropes) and then strands are untwisted into single wires as per their diameters in particular layers. Once they have been untwisted, wires are cleaned off of residues of grease and contaminations (in case of used ropes) and then straightened with the use of a hammer made of soft material, e.g. 
copper, brass or Teflon on a wooden base plate. A fter straightening, diameters of the wires are measured using a calliper or micrometer.

Strength tests are destructive, thus the use of such tests is limited. Finding a specific relation between the number of the tests and results of non-destructive tests, e.g. magnetic tests, would improve accuracy of rope condition assessment [20,21].

\section{Test results}

Effects of changes resulting from wear processes are visible especially on wires (structural elements of a rope), therefore the results of experimental tests of individual wires are given below.

A synthesis of the results of wire tensile tests are presented in Table 1. It includes maximum, minimum and average values acquired through testing of all six strands of ten tested segments of the rope. We also established rope weakenig, by comparing our test results with nominal parameters obtained from the rope manufacturer.

Table 1. Summary results of tensile force tests.

\begin{tabular}{|c|c|c|c|c|c|}
\hline \multicolumn{3}{|c|}{ Tensile force values, $\mathrm{kN}$} & \multicolumn{2}{c|}{ Force decrement } \\
\hline nomin. & $\max$ & $\min$. & average & av. value, $\mathrm{kN}$ & $\%$ \\
\hline 846 & 795 & 775 & 784 & 62 & 7,3 \\
\hline
\end{tabular}

Figure 3 presents a sample after tensile tests. A sample area reduction at the place of rupture can be seen, which is characteristic for this type of tests.

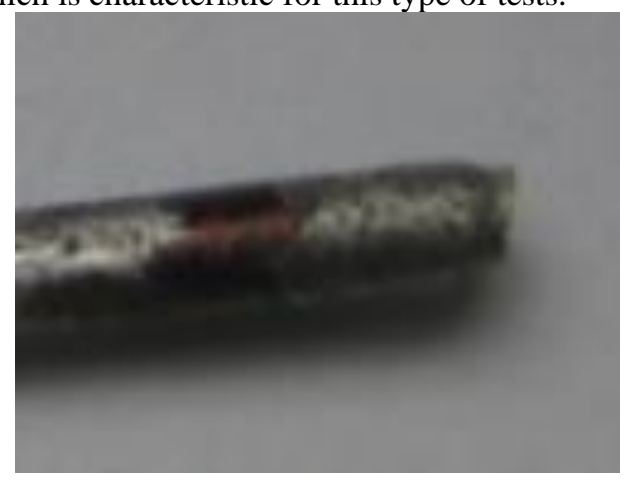

Fig. 3. A sample of external layer wire after tensile tests.

L oss of the breaking force found in our tests was 7.3\%. V alues of the breaking force given in Table 1 constitute the total of forces which break particular wires. Clearly, this force is much bigger (ca. 13\%) than the force breaking the rope in full (as per the manufacturer's certificate, this force is $756 \mathrm{kN}$ ). The fact that structural elements of a rope, which is a parallel structure, do not carry load equally, explains the above results. As it was already found, the breaking results listed in Table 1 refer to the wires of ten segments of the rope, thus they can be considered credible and enabling us to come to general conclusions.

The results of experimental bend and torsion tests of wires are included in subsequent tables, with the tested wires listed as per the strand structure layers containing these wires.

Table 2 presents the results of wire bend and torsion tests of one of six strands in one of ten tested segments of the rope. The results are presented to show the dispersion of our measurement results, especially in the torsion test. 
A very similar image was observed in all strands of the other tested segments of the rope, therefore Table 3 presents average values of the results obtained in the tests of all 6 strands in one of 10 tested sections of the rope as per respective wire layers in strands.

Table 2. Results of bend and torsion tests for exemplary strand.

\begin{tabular}{|c|c|c|c|c|c|}
\hline \multirow{2}{*}{$\begin{array}{l}\text { Strand } \\
\text { layer }\end{array}$} & \multicolumn{2}{|c|}{$\begin{array}{c}\text { Number of realized bending } \\
N_{b} / \text { torsion } N_{t} \text { cycles }\end{array}$} & \multirow{2}{*}{$\begin{array}{l}\text { Strand } \\
\text { layer }\end{array}$} & \multicolumn{2}{|c|}{$\begin{array}{c}\text { Number of realized bending } \\
N_{b} / \text { torsion } N_{t} \text { cycles }\end{array}$} \\
\hline & $N_{b}$ & $N_{t}$ & & $N_{b}$ & $N_{t}$ \\
\hline \multirow{6}{*}{$\begin{array}{l}\text { inner } \\
\text { (A) }\end{array}$} & 11 & 29 & \multirow{2}{*}{$\begin{array}{c}\text { central } \\
\text { (B) }\end{array}$} & 12 & 7 \\
\hline & 10 & 30 & & 14 & 20 \\
\hline & 8 & 21 & \multirow{14}{*}{ outer (C) } & 12 & 10 \\
\hline & 13 & 25 & & 10 & 5 \\
\hline & 9 & 21 & & 14 & 6 \\
\hline & 10 & 23 & & 15 & 4 \\
\hline \multirow{10}{*}{$\begin{array}{l}\text { central } \\
\text { (B) }\end{array}$} & 10 & 5 & & 10 & 6 \\
\hline & 11 & 21 & & 9 & 9 \\
\hline & 10 & 3 & & 9 & 7 \\
\hline & 16 & 3 & & 12 & 5 \\
\hline & 15 & 5 & & 13 & 6 \\
\hline & 10 & 20 & & 12 & 7 \\
\hline & 11 & 18 & & 10 & 12 \\
\hline & 13 & 15 & & 13 & 6 \\
\hline & 16 & 14 & & 14 & 6 \\
\hline & 10 & 20 & & - & - \\
\hline
\end{tabular}

Table 3. Summary results of bend and torsion tests for strands of exemplary segment of rope.

\begin{tabular}{|c|c|c|c|c|c|c|}
\hline \multirow{2}{*}{$\begin{array}{l}\text { Strand } \\
\text { layer }\end{array}$} & \multicolumn{5}{|c|}{$\begin{array}{c}\text { Number of realized } \\
\text { bending } N_{b} \text { /torsion } N_{t} \text { cycles } \\
\text { for individual strands }\end{array}$} \\
\cline { 2 - 8 } & 1 & 2 & 3 & 4 & 5 & 6 \\
\hline $\begin{array}{c}\text { inner } \\
\text { (A) }\end{array}$ & 10 & 10 & 11 & 11 & 11 & 11 \\
\cline { 2 - 8 } & 25 & 25 & 26 & 25 & 25 & 26 \\
\hline $\begin{array}{c}\text { central } \\
\text { (B) }\end{array}$ & 12 & 12 & 12 & 12 & 11 & 13 \\
\hline & 6 & 13 & 9 & 6 & 5 & 10 \\
\hline $\begin{array}{c}\text { outer } \\
\text { (C) }\end{array}$ & 12 & 12 & 12 & 12 & 12 & 12 \\
\hline
\end{tabular}

Table 4 includes the results of basic statistical calculations which let us draw general conclusions. The data concerns the results of tests of an exemplary segment of a rope. The table includes also minimum standard numbers of bend $N_{b}$ and torsion $N_{t}$ cycles provided for wires of a new rope. Based on this data, it is possible to assess loss of operating potential (weakening) of a rope. 
Table 4. Results of statistical calculation for bend and torsion tests.

\begin{tabular}{|c|c|c|c|c|c|c|c|c|}
\hline \multirow{2}{*}{$\begin{array}{c}\text { Strand } \\
\text { layer }\end{array}$} & \multicolumn{2}{|c|}{$\begin{array}{c}\text { Number of bending } \\
\text { cycles } N_{b}\end{array}$} & \multicolumn{2}{|c|}{ Change } & \multicolumn{2}{|c|}{$\begin{array}{c}\text { Number of torsion } \\
\text { cycles } N_{b}\end{array}$} & \multicolumn{2}{c|}{ Change } \\
\cline { 2 - 10 } & $\begin{array}{c}\text { minimum } \\
\text { for new one }\end{array}$ & $\begin{array}{c}\text { average } \\
\text { values } N_{b}\end{array}$ & value & $\%$ & $\begin{array}{c}\text { minimum } \\
\text { for new one }\end{array}$ & $\begin{array}{c}\text { average } \\
\text { values } N_{t}\end{array}$ & value & $\%$ \\
\hline $\begin{array}{c}\text { inner } \\
\text { (A) }\end{array}$ & 12 & 10,7 & 1,3 & 10,8 & 30 & 25,3 & 4,7 & 15,7 \\
\hline $\begin{array}{c}\text { central } \\
\text { (B) }\end{array}$ & 14 & 12,0 & 2,0 & 14,3 & 30 & 8,1 & 21,9 & 73,0 \\
\hline $\begin{array}{c}\text { outer } \\
\text { (C) }\end{array}$ & 13 & 12,0 & 1,0 & 7,7 & 26 & 8,0 & 16,0 & 61,5 \\
\hline
\end{tabular}

When analyzing the values listed in Tables 3 and 4, we can see only slight differences between the test results of particular layers, with the largest weakening (14\%) observed in the wires of the middle layer. We observe a completely different situation in the torsion test. While the values of weakening of the internal layer wires fall within tribological wear $(15.7 \%)$, the weakening of the wires in the middle and external layers is much more significant. This can be explained by the fact that the rope was operated in a chemically aggressive environment which means that the wires of the external and middle layers were more exposed to the environmental impact. The recorded results of such tests are presented on histograms in Figures 4 and 5.

a)

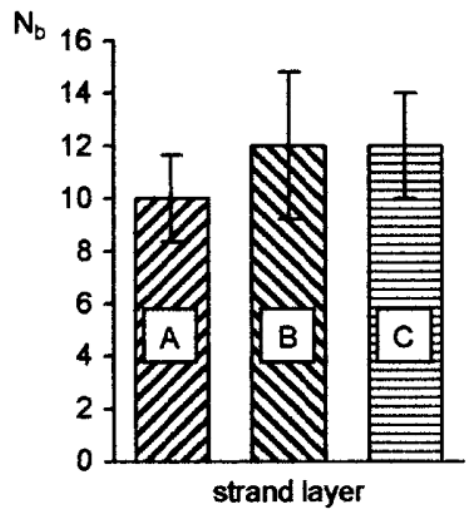

b)

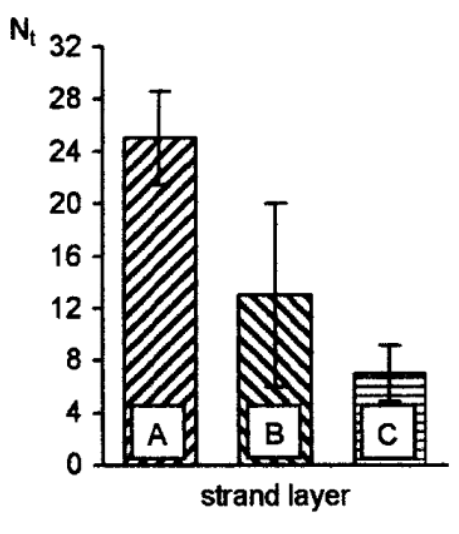

Fig. 4. Examples of average results of wire tests: a) bend ones, b) torsion ones (confidence intervals were given).

Figure 4 presents examples of the results of rope wire bend tests, while figure 4.b. presents the results of torsion tests of wires of the same strand and layer. Standard deviation values of the results are presented on the histograms. In case of the bend test, standard deviations from the results are much less than for the torsion test. In both cases we can observe the largest dispersion of the results for the middle layer resulting in the largest standard deviation measured for this layer.

Figure 5 includes the results listed in the form of histograms. The results concern all six strands of one of 10 segments of the tested rope, yet they are listed separately for each layer. 


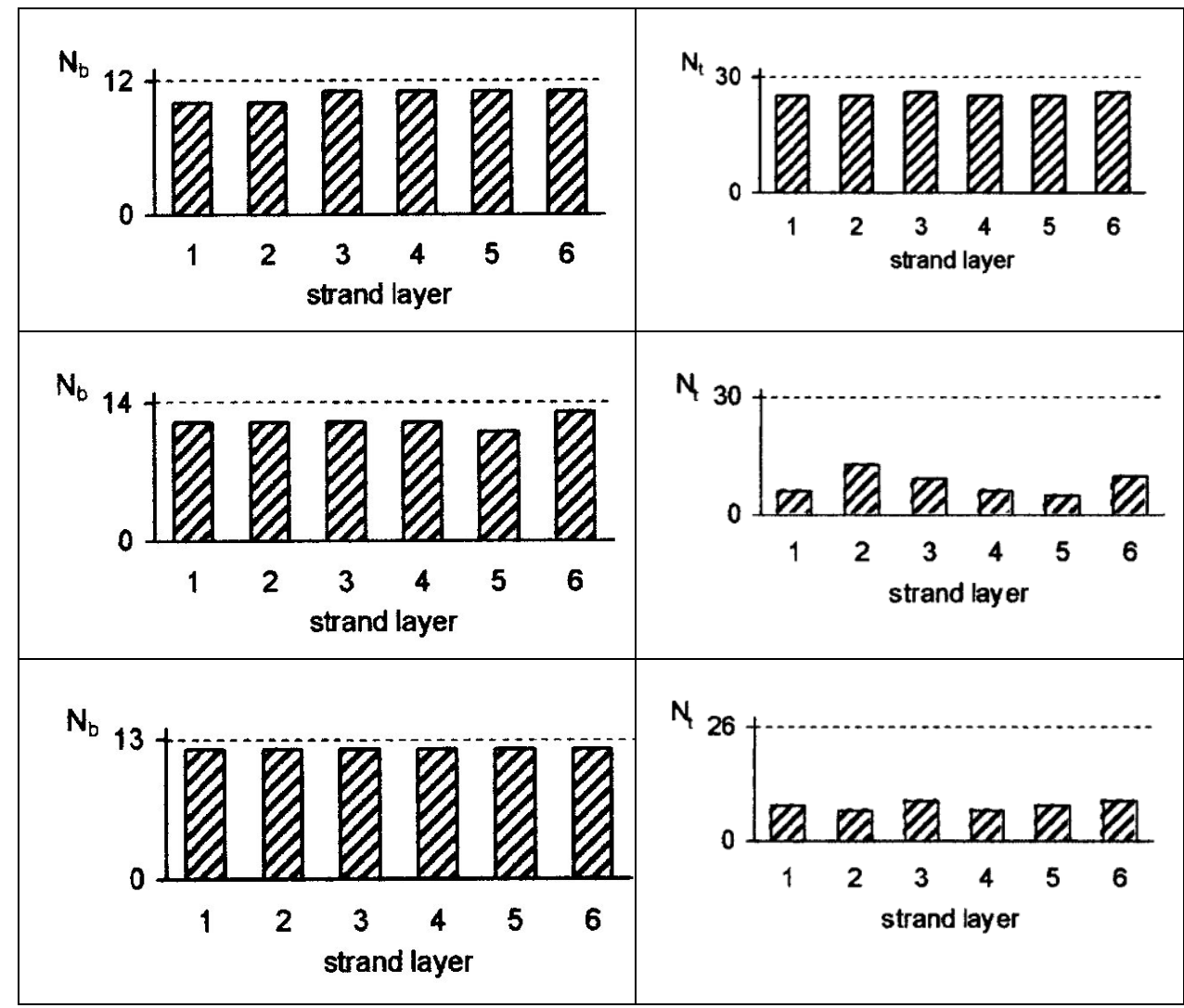

Fig. 5. Histograms of wire bend and torsion tests for one of rope segments.

The charts include the number of bend $N_{b}$ and torsion $N_{t}$ cycles required in accordance with the standards $[16,17]$ for wires of a new rope. Referring to this data we can see the level of the operating potential loss of each layer of the tested rope segment. The loss noticed after the torsion test is much bigger than after the bend test.

For sample views of wires broken due to bend tests and torsion tests, see Figure 6.

a)
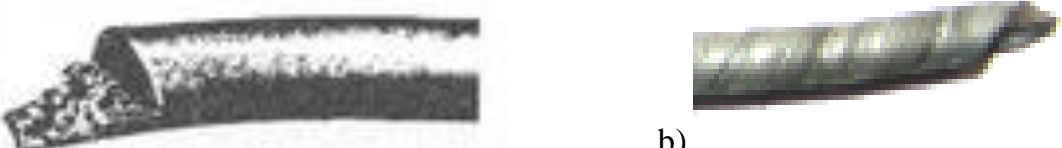

Fig. 6. Wires of bearing rope broken due to: a) bend test; $b$ ) torsion test.

In figures above characteristic forms of destruction are visible: after bend test - fatigue fracture (a), because this test is fatigue character and after torsion tests plastic deformations are visible.

\section{Summary}

There is no doubt that tests of rope condition are significant in rope system diagnostics, since the accuracy of their results have a direct influence on reliability and safety of rope operation. A comparison analysis of results of different strength parameters of ropes indicates that weakening of the rope, determined on the basis of such results, is statistically similar. An exception to this rule is found in bend tests. The results thereof suggest that bend tests cause much bigger loss of operating potential than other tests. Such differences 
are reflected in practice of the authors of this article [22, 23]. It is difficult to find substantive explanations for such huge differences, thus it seems reasonable to doubt whether conditions of performance and limit values set forth in the standard [16, 24] are upto-date and accurate.

It is required to carry out a series of verification tests in order to implement changes to the standards. Nevertheless, introduction of the above changes on the basis of such tests seems to be justified and purposeful.

\section{References}

1. M. Matuszewski, M. Słomion, A. Mazurkiewicz, D.Y. Pimenov, Assessment of friction pair elements condition based on changes in the geometric surface structure isotropicity degree. 18th International Conference Diagnostics of Machines and V ehicles. B ook Series: M A TEC W eb of Conferences, 302 (2019)

2. M. Matuszewski, M. Słomion, A. Mazurkiewicz, D.Y. Pimenov, Mathematical models of changes in the surface layer of frictional pairs as a tool to optimize the wear process, 17th International Conference Diagnostics of Machines and Vehicles. Book Series: M A TEC W eb of Conferences, 182 (2018)

3. A. Bochat, M. Zastempowski, Impact of the beater shredder design on the granulometric composition of the shredded grain material, Przemysł Chemiczny, 98, 9, 1499-1504 (2019)

4. I. Rojek, M. Kowal, A. Stoic, Predictive compensation of thermal deformations of ball screws in CNC machines using neural networks. Tehnicki V jesnik, 24, (6), 1697-1703 (2017)

5. M. Zastempowski, A. Bochat, Dynamics of the movement of the cutting assembly's cutter bar, Proceedings of the 58th International Conference Engineering of M achine Design Departments (ICM D 2017), Prague, Czech Republic, 430-435 (2017)

6. I. Rojek, A. Kujawińska, A. Hamrol, M. Rogalewicz, Artificial neural networks as a means for making process control charts user friendly. In: Burduk A., M azurkiewicz D. (eds) Intelligent Systems in Production Engineering and Maintenance - ISPEM 2017. A dvances in Intelligent Systems and Computing, 637, 168-178 (2018)

7. M. Matuszewski, Transformation of surface layer and surface isotropy changes. Proceedings of the 58th International Conference Engineering of Machine Design Departments (ICM D 2017), Prague, Czech Republic,230-235 (2017)

8. Y.B. Guo, D.K. Zhang, X.H. Y ang, C.N. Feng, S.R. Ge, Experimental research on effect of wire rope transverse vibration on friction transmission stability in a friction hoisting system. Tribology International, 115, 233-245 (2017)

9. A. Sioma, A. Tytko, Vision methods for assessing the geometrical parameters of steel ropes. Acta Mechanica et Automatica, 6, (1), 63-67 (2012)

10. M. Styp-Rekowski, E. Mańka, M. Matuszewski, M. Madej, D. Ozimina, Tribological problems in shaft hoist ropes wear process. Industrial Lubrication and Tribology, 67, 1, 47-51 (2015)

11. P. Peterka, J. K resak, S. K ropuch, G. Fedorko, V. M olnar, M. V ojtko, Failure analysis of hoisting steel wire rope, Engineering Failure A nalysis, 45, 96-105 (2014)

12. E. Mańka, M. Słomion, M. Matuszewski, Constructional features of ropes in functional units of mining shaft hoist. Acta M echanica et A utomatica, 12, 1, 66-71 (2018)

13. Standard PN-66/G-46602, Mine round-wire ropes - Hoisting triangular strand ropes

14. E. Mańka, Comparative analysis of rope testing methods in aspect of their accuracy and informativeness (Analiza porównawcza metod badania lin $w$ aspekcie zwiększenia dokładności i informatywności badań). Doctors thesis. (Publ. University of Technology and Life Sciences Bydgoszcz, 2013) 
15. Z. Lawrowski, Tribology: friction, wear, lubrication (Tribologia: tarcie, zużywanie, smarowanie), (Publ. Wrocław Technical University, Wrocław, 2008)

16. Standard PN-EN ISO 6892-1:2010, Metallic materials - Tensile testing - Part 1: Method of test in room temperature

17. Standard PN-ISO 7801: 1996, Reverse bend test

18. Standard PN-ISO 7800: 1996, Simple torsion test

19. Standard PN-ISO 3108:1996, Steel wire ropes for general purposes - Determination of actual breaking load

20. J. Kwaśniewski, Magnetic tests of steel ropes (Badania magnetyczne lin stalowych), ( Publ. A GH, Cracow, 2010)

21. A. Vorontsov, V. V olokhovsky, J. Halonen, J. Sunio, Prediction of operating time of steel wire ropes using magnetic NDT data. Proceedings of OIPEEC Conference 2007, J ohannesburg, South A frica Republic. Book of full texts, Rope - M achine Interaction, Rope M aintenance and L ubrication, J ohannesburg, 256-261, (2007)

22. M. Styp-Rekowski, E. Mańka, Environmental Factors of Rope Hoisting Shaft Wear and Reliability, in Proceedings of the $\mathrm{X}$ International Conference „Tribology and Reliability" 2010, St. Petersburg, Russia, 245-257, (2010)

23. M. Styp-Rekowski, E. Mańka, Factors determining hoisting shaft rope durability. J ournal of Polish CIM A C, 6, 3, 297-304, (2011)

24. Standard PN-ISO 3154:1997, Standed wire ropes for mine hoisting. -Technical delivery requirements 